Research Article

DOI: $10.36959 / 936 / 567$

\title{
Epidemiology of Uveitis in a Nigerian Tertiary Eye Care Centre
}

\author{
Iyiade Adeseye Ajayi, Olusola Joseph Omotoye* and F.O Adeleke \\ Department of Ophthalmology, Ekiti State University Teaching Hospital, Ado Ekiti Nigeria
}

\begin{abstract}
Background Information: To determine the epidemiology of Uveitis and patient compliance with follow up in a tertiary eye care Centre in Southwestern Nigeria.

Methods: A prospective observational study was carried out among all patients with diagnosis of uveitis in our centre. This was done with the aid of a structured questionnaire. Data were entered into SPSS version 20 and analyzed for simple frequency, means, standard deviation and comparative analysis of some variables. $P<0.05$ was considered to be significant.
\end{abstract}

Results: Uveitis constituted $1.73 \%$ of the total number of new cases seen during the study period with a male to female ratio of 1:1. Ages ranged from 8 years to 110 years. Unilateral cases accounted for 159 (93\%). Eye ache (64.9\%), redness (59.6\%), blurring of vision (42.7\%) were the leading complaints among the patients. Anterior uveitis constituted 109 (63.7\%) of total number of cases. Majority of the trauma related cases presented within 7 days of the onset of symptoms. Patients with intermediate uveitis had the best compliance with follow up appointments.

Conclusion: Anterior uveitis was the leading anatomical type in our centre. There was delayed presentation in more than half of the patients. Some patients presented as late as 3 years after the onset of symptoms. We recommend health education for early presentation of all cases of redness to eye care centers.

\section{Keywords}

Epidemiology, Uveitis, Eye-care

\section{Introduction}

Uveitis could be defined as inflammation of the uveal tract with or without the involvement of adjacent ocular structures [1]. It is a major cause of visual loss both in developed and developing nations of the world [2] It carries risk of ocular morbidity being accountable for $25 \%$ of legal blindness in the developing world [1,3-6]. The incidence has been observed to be on the increase in recent decades $[7,8]$. This has been attributed to the increasing number of the primary or idiopathic type as well as improved diagnostic facilities for the secondary type which can be infectious on non-infectious [8]. The chronic and complicated types were found to be more in referral or tertiary centres according to some reports while anterior uveitis was found to constitute the majority (90.6\%) in the non-referral centres [8]. The etiologies of uveitis are known to vary in different populations depending on the country, race and socioeconomic status $[7,9]$. There are limited information on the epidemiology of uveitis [10].

The knowledge of region specific variation in pattern is essential in determining final diagnosis as well as in health planning. This study was carried out to review the epidemiology of uveitis in our tertiary eye care facility, prevalence of the different types of uveitis, pattern of presentation as well as pattern of compliance with follow up among our patients.

\section{Materials and Methods}

Ekiti State University Teaching Hospital provides eye care for over 2.38 million citizens of the state [11] as well as some patients from the neighbouring South western states of the country. A prospective questionnaire based observational study was carried out to determine the prevalence, pattern of presentation and follow up of all patients who presented with features of any uveitis at our eye care centre between July 2012 and July 2018. Details of age, sex, occupation, symptoms and duration before presentation were recorded. Presenting visual acuity (PVA), ocular findings from dilated fundoscopy, slit lamp examination, intraocular pressure measurement with applanation tonometer and results of investigations as well as visual acuity at 3 months after presentation, duration of follow up and complications were documented. Data were

*Corresponding author: Olusola Joseph Omotoye, Department of Ophthalmology, Ekiti State University Teaching Hospital, Ado Ekiti Nigeria, Tel: +234-8034976221

Accepted: January 22, 2019

Published online: January 24, 2019

Citation: Ajayi IA, Omotoye OJ, Adeleke FO (2019) Epidemiology of Uveitis in a Nigerian Tertiary Eye Care Centre. J Ophthalmic Res Ocular Care 3(1):50-54 
entered into Statistical Package for Social Sciences (SPSS version 25 ) and analyzed.

\section{Results}

One hundred and seventy one patients were seen during the period of study. This constituted $1.73 \%$ of the total number of new patients seen within the period of study. There were 85 males (49.7\%) and 86 females (50.3\%) with a male to female ratio of 1:1. The minimum age was 8 years while the maximum age was 110 years. There were 15 children (8.7\%) aged 16 years and below and $152(90.1 \%)$ adults. The mean age of the patients was 37.11 years $( \pm 15.28)$. Unilateral cases accounted for 159 (93\%) while $12(7.0 \%)$ cases were bilateral. One hundred and sixty four $(95.9 \%)$ respondents had some forms of formal education while 4 (2.3\%) had no formal education.

The duration of presentation ranged from 1 day to 3

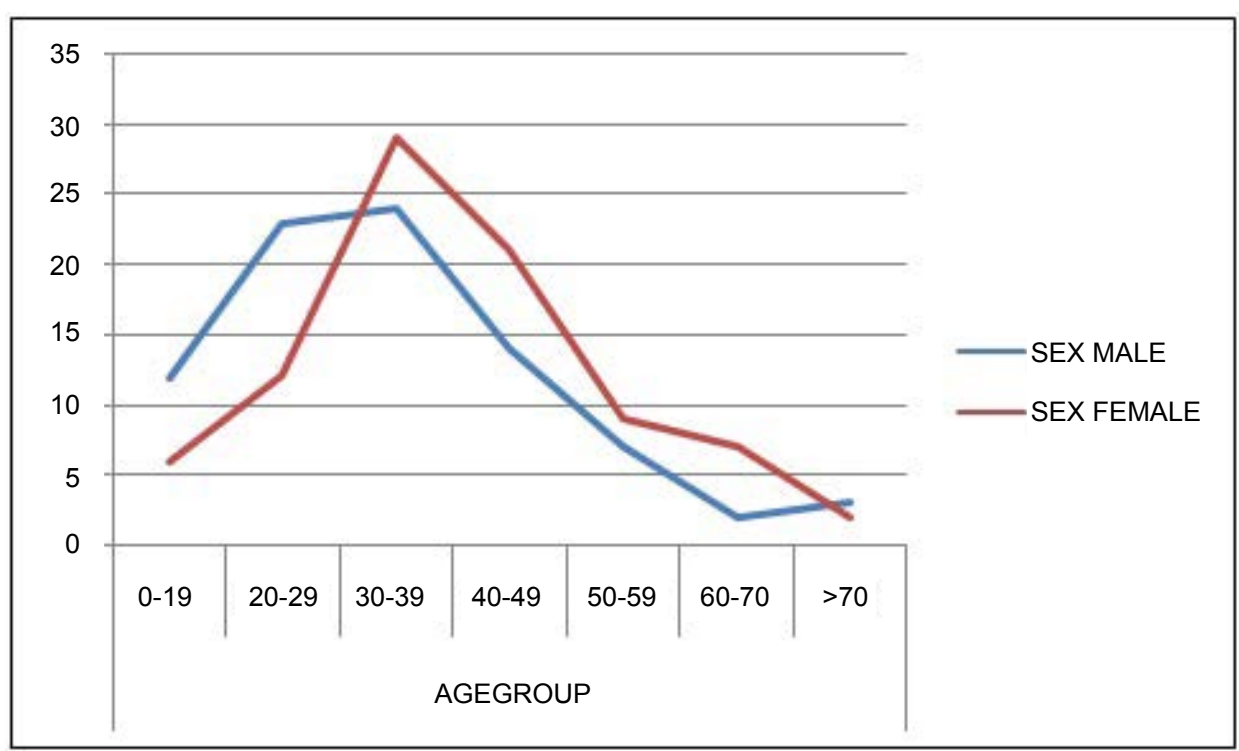

Figure 1: Age-group vs. sex distribution of patients. The peak age of incidence was 30-39 years in both genders.

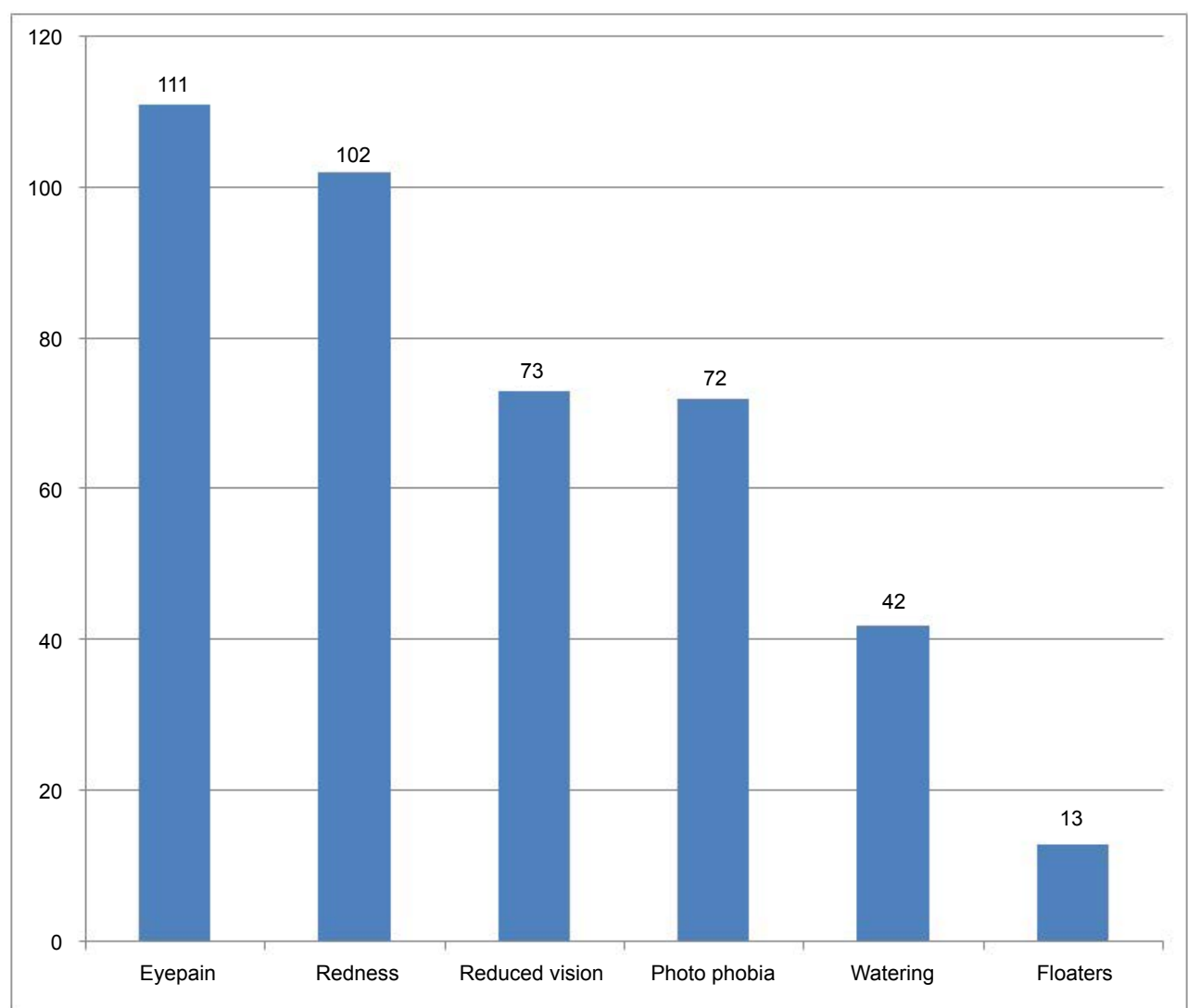

Figure 2: Eye Complaints. It shows the pattern of eye complaints among patients. Most patients had more than one eye complaints at the time of presentation. 
years with a mean of 49.6 days. About $71(41.5 \%)$ presented within 7 days from the onset of symptoms while 100 (58.5\%) presented after 7 days from the onset of symptoms. Trauma related cases accounted for 48 (28.1\%) of cases of uveitis. Infectious causes like Tuberculosis accounted for 6 (3.5\%), HIV/AIDS 3 (1.8\%), presumed Toxoplasmosis accounted for 49 (28.7\%). Trauma related cases were observed to have a greater odd of presentation within 7 days of onset of symptoms (RR 2.568 Cl 1.546-4.266 P value < 0.001) for those in the paediatric age group $8(50 \%)$ of cases of uveitis were trauma related. Onset of symptoms was acute in 131 (76.6\%) cases. The course of disease was recurrent in 17 (9.9\%) and chronic in 12 (7.0\%).

At 4 weeks follow up there were 87 (50.9\%) compliance and $65(38.0 \%)$ at 12 weeks. There was compliance with follow up in 44 males and 43 females at 4 weeks while 29 males and 36 females complied with follow up at 12 weeks. (RR: $1.121 \mathrm{Cl} 0.830-1.514 \mathrm{P}=0.283$ ).

At 12 weeks follow up there were 58 (36.4\%) of total unilateral cases and 7 (58.3\%) of total bilateral cases. 45 cases (26.3\%) had normal visual acuity, 13 (7.6\%) had visual

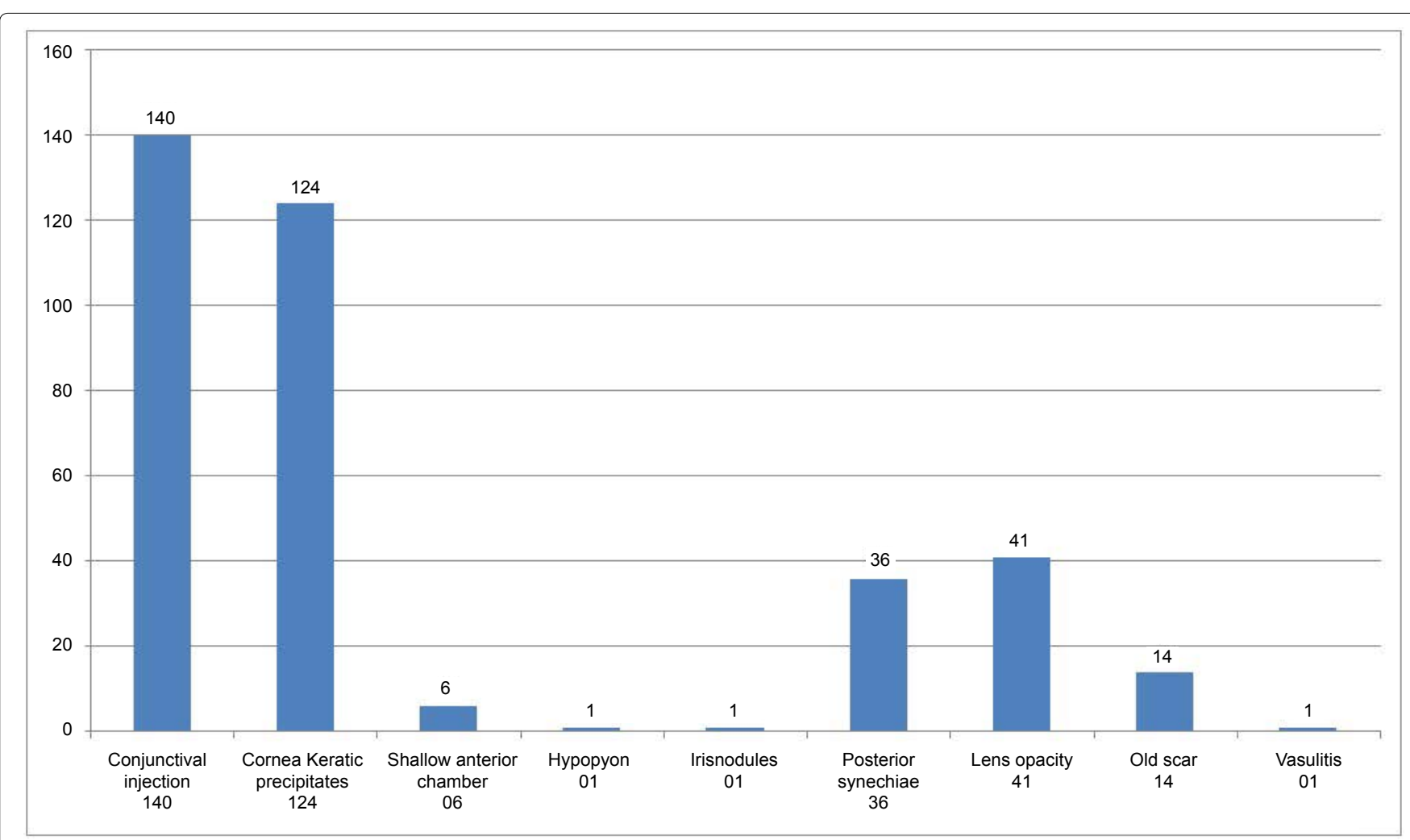

Figure 3: Ocular findings among patients.

Conjunctival injection (81.9\%) and keratic precipitates (72.5\%) were the leading ocular findings at presentation. Intraocular pressure ranged between $2 \mathrm{mmHg}$ and $58 \mathrm{mmHg}$.

Table 1: Final diagnosis among patients.

\begin{tabular}{|l|l|l|l|}
\hline Diagnosis & $\mathbf{1} \mathbf{1 6}$ years $\mathbf{n}(\%)$ & $\mathbf{1 6}$ years $\mathbf{n}(\%)$ & Total $\mathbf{n}(\%)$ \\
\hline Anterior Uveitis & $11(6.4 \%)$ & $98(57.3 \%)$ & $109(63.7 \%)$ \\
\hline Panuveitis & $2(1.1 \%)$ & $36(21.1 \%)$ & $38(22.2 \%)$ \\
\hline Posterior Uveitis & $2(1.1 \%)$ & $18(10.6 \%)$ & $20(11.7 \%)$ \\
\hline Intermediate Uveitis & - & $04(2.3 \%)$ & $04(2.3 \%)$ \\
\hline
\end{tabular}

Children constituted only about one tenth of the total number of patients. Anterior uveitis was the most common variety based on primary site of involvement.

Table 2: Anatomical type of uveitis and Presenting Visual Acuity.

\begin{tabular}{|c|c|c|c|c|}
\hline \multirow[t]{2}{*}{ Type of Uveitis } & \multicolumn{4}{|c|}{ Presenting Visual Acuity } \\
\hline & $\geq 6 / 18 \mathrm{n}(\%)$ & $6 / 18-6 / 60$ n (\%) & 6/60-3/60 n (\%) & $<3 / 60 \mathrm{n}(\%)$ \\
\hline Anterior Uveitis & $71(41.5)$ & $24(14.0)$ & $7(4.1)$ & $7(4.1)$ \\
\hline Posterior Uveitis & $3(1.8)$ & $7(4.1)$ & $5(2.9)$ & $5(2.9)$ \\
\hline Intermediate Uveitis & $1(0.6)$ & $2(1.2)$ & $0(0)$ & $1(0.6)$ \\
\hline Panuveitis & $12(7.0)$ & $4(2.3)$ & $6(3.5)$ & $16(9.4)$ \\
\hline Total & 87 (50.9) & $39(22.8)$ & $18(10.5)$ & $29(17.0)$ \\
\hline
\end{tabular}

There were 29 (17.0\%) blind eyes at presentation. 
Citation: Ajayi IA, Omotoye OJ, Adeleke FO (2019) Epidemiology of Uveitis in a Nigerian Tertiary Eye Care Centre. J Ophthalmic Res Ocular Care 3(1):50-54

Table 3: Pattern of compliance with follow up for various anatomical types of Uveitis.

\begin{tabular}{|l|l|l|l|}
\hline Type of uveitis & $\mathbf{4}$ weeks follow up $\mathbf{n}(\%)$ & $\mathbf{1 2}$ weeks follow up $\mathbf{n}$ (\%) & Difference in follow up $\mathbf{n}(\%)$ \\
\hline Anterior Uveitis & $56(32.7)$ & $40(23.4)$ & $16(9.4)$ \\
\hline Panuveitis & $17(9.9)$ & $12(7.0)$ & $5(2.9)$ \\
\hline Posterior Uveitis & $11(6.4)$ & $10(5.9)$ & $1(0.6)$ \\
\hline Intermediate Uveiti & $03(1.8)$ & $03(1.8)$ & $0(0)$ \\
\hline Total & $87(50.9)$ & $65(38.0)$ & $22(12.0)$ \\
\hline
\end{tabular}

impairment and 7 (4.1\%) had blindness.

Structural complications include cataract 6 (3.5\%), Retinal detachment $2(1.2 \%)$, Macular scar $3(1.8 \%)$, ciliary shutdown with hypotony 1 (0.6\%), Irido-dialysis 1 (0.6\%).

Uveitis constituted $1.73 \%$ of the total new patients seen during the study period. There was no significant difference in the gender prevalence among patients in this study as there were almost equal number of males and females. This is in agreement with some reports among adults and children in developed and developing worlds [2,12,13]. A slight prevalence among women has been found in some other studies in developed nations [2]. Children constituted only about one tenth of the total number of patients. This could be because it has been observed that uveitis affects children less frequently $[2,7,14,15]$. However, it is worthy of note here that $50 \%$ of the children in this study had trauma related uveitis. As shown in Figure 1 the incidence of uveitis peaked between 30-49 years age group. The mean age of the patients was $37.1 \pm 15.3$ years. This is similar to the mean age in most studies which have been observed to be between 35 and 45 years of age by researchers in some developing and developed nations $[1,2,7]$ but lower than some others where a mean age of $53 \pm 13$ years was reported [16]. In all of these, the common point is that uveitis is a disease of young adults [7] especially those in the working age group. Majority (93\%) of the cases were unilateral. This is similar to Eduardo [17] but more than twice the frequency in Brazil [2]. Anterior uveitis was the commonest anatomical type in our study with trauma related cases accounting for $28.1 \%$ of all. This corresponds to documented findings from previous studies $[2,7,8]$. Anterior uveitis resulting from trauma was the most common ocular disorder among sawmill workers in Southeastern Nigeria [18]. This was followed by Panuveitis accounting for $22.2 \%$ and posterior uveitis which accounted for $11.7 \%$. Panuveitis was found to be quite common in Japan because of the high prevalence of conditions like Sarcoidosis and Behcet syndrome [19]. Presumed Toxoplasmosis 49 (28.7\%) was the leading infectious cause among patients with panuveitis and posterior uveitis. Diagnosis for Toxoplasmosis in the case of our patients was based on clinical judgment due to the lack of diagnostic facilities for Toxoplasmosis in our practice centre [20-22].

Early diagnosis and adequate treatment can help to reduce or prevent damage in many uveitis entities [5]. The duration of symptoms before presentation ranged from a day to as long as 3 years in some patients with a mean duration of 49.6 days. Less than half of the patients presented within 7 days from the onset of symptoms. Patients with trauma related cases had greater odd of presenting within 7 days from the onset of symptoms. This still emphasizes the need for improved education among our population because the visual outcome among patients can be largely affected by the promptness with which patients present for interventions. Infectious cases like Tuberculous uveitis (3.5\%) among others have been reported to be more frequent in developing countries [8].

Figure 2 shows the high prevalence of symptoms of active disease among our patients. The 2 leading ocular symptoms were eye pain $(64.9 \%)$ and redness $(59.6 \%)$. Reduced vision $(42.7 \%)$ and photophobia $(42.1 \%)$ were also common symptoms among the study subjects. This correlates greatly with the symptoms of anterior and panuveitis which are the 2 leading disorders in this study. It is worrisome that in spite of the symptoms of acute disorders, many of the patients (58.5\%) still presented beyond one week after the onset of symptoms.

There were $29(17.0 \%)$ blind eyes at presentation, 18 (10.5\%) had moderate visual impairment while 39 (22.8\%) had mild to moderate visual impairment as shown in Table 2. Uveitis mainly posterior uveitis is an important cause of blindness resulting in $10 \%$ of all cases of blindness. The exact impact of uveitis on worldwide blindness is unknown. In a study conducted in west Africa, uveitis including onchocerciasis ranked as the second cause of blindness accounting for $24 \%[23,24]$. Conjunctival injection $(81.9 \%)$ and keratic precipitates $(72.5 \%)$ were the leading ocular findings at presentation. Less frequent were hypopyon, iris nodules and vasculitis as shown in Table 3. Since pathognomonic findings like keratic precipitates can only be appreciated with slit lamp examination patients need to be educated to present every case of painful redness to eye care centres within the $1^{\text {st }}$ week of onset of symptoms.

Intraocular pressure levels in uveitis can be elevated primarily from blockage of trabecular meshwork by inflammatory cells with or without inflammation of the trabecular meshwork. Posterior synechiae with pupil block can also lead to impairment of aqueous flow with resultant elevation of intraocular pressure [9,25-28]. Steroid use can also be the cause of elevated intraocular pressure among steroid responders. On the other hand, low intraocular pressure could result from ciliary shutdown, increased uveoscleral outflow or presence of complications like retinal detachment $[29,30]$. In the case of our patients, intraocular pressure ranged from $2 \mathrm{mmHg}$ to $58 \mathrm{mmHg}$. Two patients (1.2\%) had retinal detachment while 36 patients (21.1\%) had posterior synechiae Figure 3. One other patient had low pressure as a result of ciliary shutdown with hypotony. The large number of patients with posterior synechiae could be the result of delayed presentation among our patients.

The pattern of compliance with follow up visits as shown in Table 2 was higher among patients with intermediate 
uveitis, and posterior uveitis. It was lower among patients with anterior uveitis and pan uveitis. Although there were more females than males at 12 weeks after presentation, the gender of the patient did not have any statistically significant influence of the compliance with follow up appointments. $(P=0.283)$ There were fewer patients at 12 weeks follow up after presentation for all patients except the people with intermediate uveitis. Bilateral cases also had greater compliance with follow up.

The visual acuity among the patients at 12 weeks follow up revealed 13 (7.6\%) with visual impairment and 7 (4.1\%) with blindness. This corroborates the fact that uveitis is a potentially blinding eye condition especially in the developing nations of the world [1,3].

In conclusion Uveitis is a common condition with risk of ocular morbidity. Anterior uveitis was the most common anatomical variety. Many patients presented to the hospital beyond 1 week after the onset of symptoms.

We recommend health education for all patients especially those with redness and blurring of vision to enhance early presentation and limit or prevent ocular morbidity and visual loss that could result from delayed presentation and inappropriate treatment.

\section{References} eye: Incidence, patterns, and differential diagnosis. Journal of ophthalmology 2015.

2. Gameiro Filho AR, Albuquerque AFd, Martins DGdS, et al. (2017) Epidemiological analysis of cases of uveitis in a tertiary Hospital. Revista Brasileira de Oftalmologia 76: 181-185.

3. Zheng $Y$, Zhang L-X, Meng Q-L, et al. (2015) Clinical patterns and characteristics of uveitis in a secondary hospital in southern China. Int J Ophthalmol 8: 337-341.

4. Nizamuddin SH, Bawazeer AM (2013) Causes of uveitis in a tertiary center in Western Saudi Arabia. Saudi medical journal 34: 379-387.

5. Suttorp-Schulten M, Rothova A (1996) The possible impact of uveitis in blindness: A literature survey. The British journal of ophthalmology 80: 844-848.

6. London NJ, Rathinam SR, Cunningham ET (2010) The epidemiology of uveitis in developing countries. Int Ophthalmol Clin 50: 1-17.

7. Rathinam S, Namperumalsamy P (2007) Global variation and pattern changes in epidemiology of uveitis. Indian J Ophthalmol 55: 173.

8. Hormoz C, Rostami M, Mohammadi S-F, et al. (2009) Epidemiology and prevalence of uveitis: Review of literature. Iranian Journal of Ophthalmology 21: 4-16.

9. Bodaghi B, Cassoux N, Wechsler B, et al. (2001) Chronic severe uveitis: Etiology and visual outcome in 927 patients from a single center. Medicine 80: 263-270.

10. Miserocchi E, Fogliato G, Modorati G, et al. (2013) Review on the worldwide epidemiology of uveitis. Eur J Ophthalmol 23: 705-717.
1. Abdulaal MR, Abiad BH, Hamam RN (2015) Uveitis in the aging

11. Momoh J, Oladebeye D (2010) Assessment of awareness, attitude and willingness of people to participate in household solid waste recycling programme in Ado-ekiti, Nigeria. Journal of Applied Sciences in Environmental Sanitation 5.

12. Çakar Özdal MP, Yazici A, Tüfek M, et al. (2014) Epidemiology of uveitis in a referral hospital in Turkey. Turk J Med Sci 44: 337-342.

13. Patel H, Goldstein D (2003) Pediatric uveitis. Pediatr Clin North Am 50: 125-136.

14. Ajaiyeoba A, Isawumi M, Adeoye A, et al. (2006) Prevalence and causes of eye diseases amongst students in south-western Nigeria. Annals of African Medicine 5: 197-203.

15. Tugal-Tutkun I (2011) Pediatric uveitis. Journal of ophthalmic \& vision research 6: 259.

16. González MM, Solano MM, Porco TC, et al. (2018) Epidemiology of uveitis in a US population-based study. J Ophthalmic Inflamm Infect 8: 6.

17. Pérez-Guijo V, Santos-Lacomba $M$, Sánchez-Hernández $M$, et al. (2004) Tumour necrosis factor-alpha levels in aqueous humour and serum from patients with uveitis: the involvement of HLA-B27. Curr Med Res Opin 20: 155-157.

18. Uhumwangho O, Njinaka I, Edema O, et al. (2010) Occupational eye injury among sawmill workers in Nigeria. Asian Journal of Medical Sciences 2: 233-236.

19. Wakabayashi T, Morimura Y, Miyamoto Y, et al. (2003) Changing patterns of intraocular inflammatory disease in Japan. Ocul Immunol Inflamm 11: 277-286.

20. Bosch-Driessen LE, Berendschot TT, Ongkosuwito JV, et al. (2002) Ocular toxoplasmosis: Clinical features and prognosis of 154 patients. Ophthalmology 109: 869-878.

21. Ajayi IA, Omotoye OJ, Ajite KO, et al. (2016) Retinal Disorders in a Tertiary Eye Centre in Nigeria. Pakistan Journal of Ophthalmology 32: 153.

22. Ohiolei JA, Isaac C (2016) Toxoplasmosis in Nigeria: The story so far (1950-2016): A review. Folia parasitologica 63: 1.

23. Ronday M, Stilma J, Barbe R, et al. (1995) Blindness from uveitis in a hospital population in Sierra Leone. Ophthalmic Literature 3: 201.

24. Ronday M, Stilma J, Barbe R, et al. (1994) Blindness from uveitis in a hospital population in Sierra Leone. Br J Ophthalmol 78: 690-693.

25. Sng CC, Ang M, Barton K (2015) Uveitis and glaucoma: new insights in the pathogenesis and treatment. Prog Brain Res 221: 243-269.

26. Siddique SS, Suelves AM, Baheti U, et al. (2013) Glaucoma and uveitis. Survey of Ophthalmology 58: 1-10.

27. Baneke AJ, Lim KS, Stanford M (2016) The pathogenesis of raised intraocular pressure in uveitis. Curr Eye Res 41: 137-149.

28. Ritch R (1981) Pathophysiology of glaucoma in uveitis. Transactions of the ophthalmological societies of the United Kingdom 101: 321-324.

29. Tran VT, Mermoud A, Herbort CP (2000) Appraisal and management of ocular hypotony and glaucoma associated with uveitis. Int Ophthalmol Clin 40: 175-203.

30. Daniel E, Pistilli M, Pujari SS, et al. (2012) Risk of hypotony in noninfectious uveitis. Ophthalmology 119: 2377-2385.

DOI: $10.36959 / 936 / 567$

Copyright: (C) 2019 Ajayi IA, et al. This is an open-access article distributed under the terms of the Creative Commons Attribution License, which permits unrestricted use, distribution, and reproduction in any medium, provided the original author and source are credited.
SCHOLARS.DIRECT 